\title{
Retraction of: microRNA-34a-Upregulated Retinoic Acid-Inducible Gene-I Promotes Apoptosis and Delays Cell Cycle Transition in Cervical Cancer Cells, by Wang J-H, et al. DNA Cell Biol 2016;35(6):267-279; DOI: 10.1089/dna.2015.3130.
}

\begin{abstract}
A REPORT BY AN INDEPENDENT science integrity consultant was delivered to the Editor-in-Chief of DNA and Cell Biology whereby a set of 39 papers from the author group of Hua Tang at Tianjin Medical University "appear to contain identical or overlapping images that represent different experiments, mostly colony formation assays or transwell experiments. The problems in each individual paper might seem minor, but together, the large amounts of overlapping images might suggest a much broader problem." A corresponding link to PubPeer.com was provided. ${ }^{1}$

The report noted that nearly all of the 39 papers in question have been funded by multiple grants of the National Natural Science Foundation of China.

The Editor-in-Chief of DNA and Cell Biology reviewed the information and found that the digital manipulation of images in figures 1,3 , and 4 is scientific misconduct. The paper is officially retracted based on the image manipulation alone, but also due to the appearance of a pattern of malfeasance from this lab.
\end{abstract}

DNA and Cell Biology is committed to upholding the standards of scientific publishing and the community it serves and will not tolerate any improprieties.

\section{Reference}

1. https://pubpeer.com/publications/E6A1489DDAA4412BA1027C235C4E8C 